\title{
A Note on the Activation Energy for the Viscous Flow
}

\author{
of Aqueous Solutions
}

\author{
Reita TAMAMUSHI \\ Received September 28, 1985 ; Accepted December 6, 1985
}

\begin{abstract}
The temperature dependence of the activation energy for viscous flow of concentrated aqueous solutions was examined with more than twenty electrolytes and some nonelectrolytes in the temperature range 15-55 - C. All solutions studied gave temperature-dependent activation energies which decrease with increasing temperature. In concentrated solutions, the magnitude of the change in activation energy with temperature was relatively small for such electrolytes like KCl, RbCl, Csc1, etc., while it was larger for sucrose and the electrolytes containing multiply-charged ions. The result is discussed in terms of the model for water structure.
\end{abstract}

The temperature dependence of viscosity can be discussed in terms of the activation energy, Evis, as defined by the relation,

$$
\underline{E}_{\mathrm{vis}}=\underline{R}\left\{\mathrm{~d} \ln \left(\eta / \eta \eta^{-}\right) / \mathrm{dT} \underline{T}^{-1}\right\}
$$

where $\eta$ is the viscosity, $\eta$ the standard viscosity (usually 1 cP), T the absolute temperature, and $\underline{R}$ the gas constant. If the activation energy remains constant in a given range of temperature, the variation of viscosity with temperature can be represented by the Arrhenius-type equation,

$$
\ln (\eta / \eta)=\underline{A}+\underline{E}_{v i s} / \underline{R T}
$$

where $A$ is a constant.

\begin{abstract}
Simple nonassociated liquids usually satisfy the Arrhenius-type equation with activation energies independent of temperature. Some polar liquids, however, are known to give activation energies which significantly vary with temperature ${ }^{1}$. Water is a typical example of the latter. Table 1 represents the variation of the activation energy, E, , with temperature for several liquids at $25^{\circ} \mathrm{C}$, where the valyes of (dEvis/dT) $25{ }^{\circ} \mathrm{C}$ were calculated using viscosity data given in literature ${ }^{2}$.

The temperature-dependent activation energy for the viscous flow of water is considered to be due to the structural change of water with temperature; with increasing temperature the jce-like structure of water will break down, which will give smaller activation energies ${ }^{3}$.
\end{abstract}

Table 1. Temperature derivatives of the activation energy for viscous flow of some liquids at $25^{\circ} \mathrm{C}$

$\begin{array}{ll}\text { Liquid } & (\mathrm{dE} \mathrm{Vis} / \mathrm{dT}) \\ \text { Water } & -0.124 \\ \text { Aniline } & -0.209 \\ \text { Ethanol } & +0.046 \\ \text { Benzene } & -0.019 \\ \text { Carbon tetrachloride } & -0.008\end{array}$

Faculty of Education, Fukushima University (Asakawa, Matsukawa-machi, Fukushima 960-12)

Key Words: Viscosity, Activation energy, Electrolyte solution, Hydration 
Aqueous electrolyte solutions, when they are dilute, generally exhibit similar departure from the Arrhenius-type linear relationship to that observed for liquid water. At higher concentrations, however, conflicting results have been reported in literature. For example, the viscosity data for aqueous solutions of $\mathrm{NaSCN}, \mathrm{NaClO}_{4}$, and $\mathrm{NaCl}$ were fourd by Miller and Doran $)_{\text {not to }}$ satisfy the Arrhenius-type equation (2) in the concentfation range 2-10 mol $\mathrm{dm}^{-3}$. On the other hand, Suryanarayana and venkatesan 5 ) reported that the linear relationship between $\log (\eta / \eta)^{-}$and $1 / T$ exists in aquegous solutions of $\mathrm{KCl}, \mathrm{NaCl}, \mathrm{KNO}_{3}, \mathrm{CuSO}_{4}$ and $\mathrm{ZnSO}_{4}$ at concentrations $>1$ mol dm -3 .

stokes and Mills pointed out in their monograph ${ }^{6}$ that the linearity implied by the Arrhenius-type equation, if it really exists iq, some electrolyte solutions, may be explained in terms of Satoh's model () which assumes the break down of the normal water structure by the interaction between ionic hydration shells in concentrated solutions. They also mentioned, however, that "in view of the conflicting experimental evidence in concentrated solutions however, such concepts must remain rather conjectural."

The comment of Stokes and Mills encouraged the present author to examine the temperature dependence, of the activation energy as defined by eq. (1) using recent viscosity data for aqueous splutions of the following solutes at concentrations greater than $0.05 \mathrm{~mol} \mathrm{~kg}^{-1}$ and in the temperature range $15-55^{\circ} \mathrm{C}$ : $\mathrm{MCl}\left(\mathrm{M}=\mathrm{Li}, \mathrm{Na}, \mathrm{K}, \mathrm{Rb}, \mathrm{Cs}, \mathrm{NH}_{4}\right), \mathrm{MCl}_{2}(\mathrm{M}=\mathrm{Mg}, \mathrm{Ca}, \mathrm{Sr}, \mathrm{Ba}), \mathrm{LaCl} \mathrm{L}_{3}, \mathrm{NaBr}, \mathrm{KBr}$,

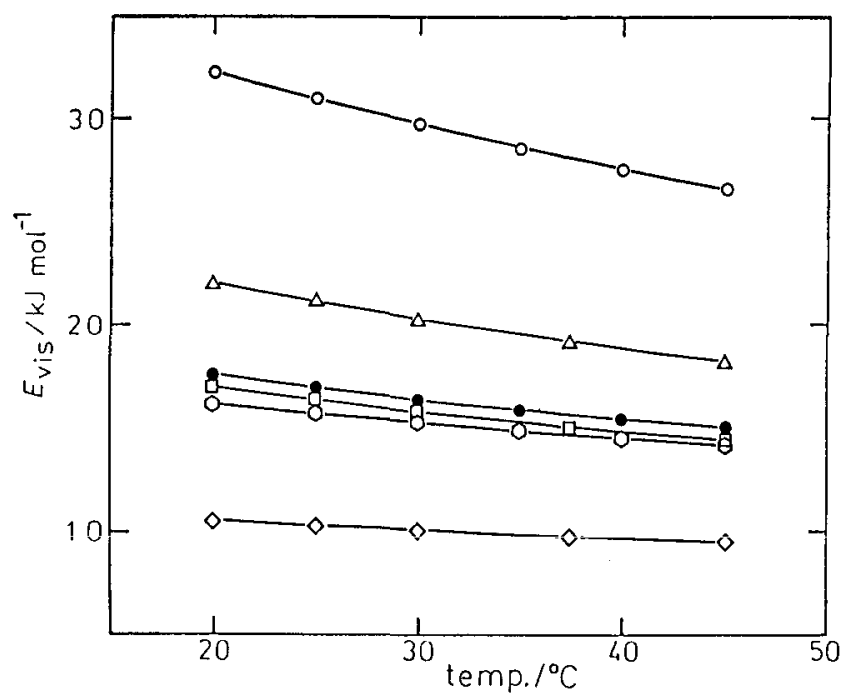

Fig. 1 Activation energy for the viscous flow of some concentrated aqueous solutions as a function of temperature: $\mathrm{H}_{2} \mathrm{O}, \square 3 \mathrm{~mol} \mathrm{~kg}^{-1} \mathrm{NaCl}, \diamond 8 \mathrm{~mol}$ $\mathrm{kg}^{-1} \mathrm{CsCl}, \triangle 5 \mathrm{~mol} \mathrm{~kg}^{-1} \mathrm{MgCl}_{2}, \mathrm{O}_{3}$ mol $\mathrm{kg}^{-1}$ sucrose, $\bigcirc 8$ mol $\mathrm{kg}^{-1}$ urea

$\mathrm{NaNO}_{3}, \mathrm{KNO}_{3}, \mathrm{Cd}\left(\mathrm{NO}_{3}\right)_{2}, \mathrm{Na}_{2} \mathrm{SO}_{4}, \mathrm{MgSO}_{4}, \mathrm{ZnSO}_{4}, \mathrm{NiSO}$, acetic acid, potassium acetate, urea and sucrose. All the solutions studied gave the temperaturedependent activation energies; the activation energy always decreases with increasing temperature.

Some examples of the temperature dependence of the activation energy, Eyis. are shown in Figs. 1 and 2 , where $\underline{E}_{y i s}$ at a constant composition is plotted against temperature in Fig. 1 and the quantity (dE $\underline{y j}_{\text {is }} / \mathrm{d} T$ ) at $25 \cdot \mathrm{C}$ is plotted against molality in Fig. 2 in order to demonstrate the effect of solution composition on the variation of $\underline{E}_{v i s}$ with temperature.

As can be seen from Fig. 2, the change of (dE $\underline{v i s}_{\text {is }}$, with molality depends on the nature of solute. In concentrated solutions, the magnitude of (dE $\mathrm{vis} / \mathrm{dT}$ ) becomes smaller with increasing concentration for those solutes known as 
structure-breakers ( $\mathrm{KCl}, \mathrm{RbCl}, \mathrm{CsCl}$ and $\left.\mathrm{NH}_{4} \mathrm{Cl}\right)$, while it becomes larger for sucrose and the electrolytes $\left(\mathrm{MgCl}_{2}, \mathrm{LaCl}_{3}, \mathrm{Cd}\left(\mathrm{NO}_{3}\right)_{2}, \mathrm{MgSO}_{4}\right.$, etc.) containing multiply-charged ions which have a net structure-forming effect. Such solutes like LiCl, $\mathrm{NaCl}$ and urea do not change ( $\mathrm{dE}_{\mathrm{vis}} / \mathrm{dT}$ ) significantly upon changing concentration.

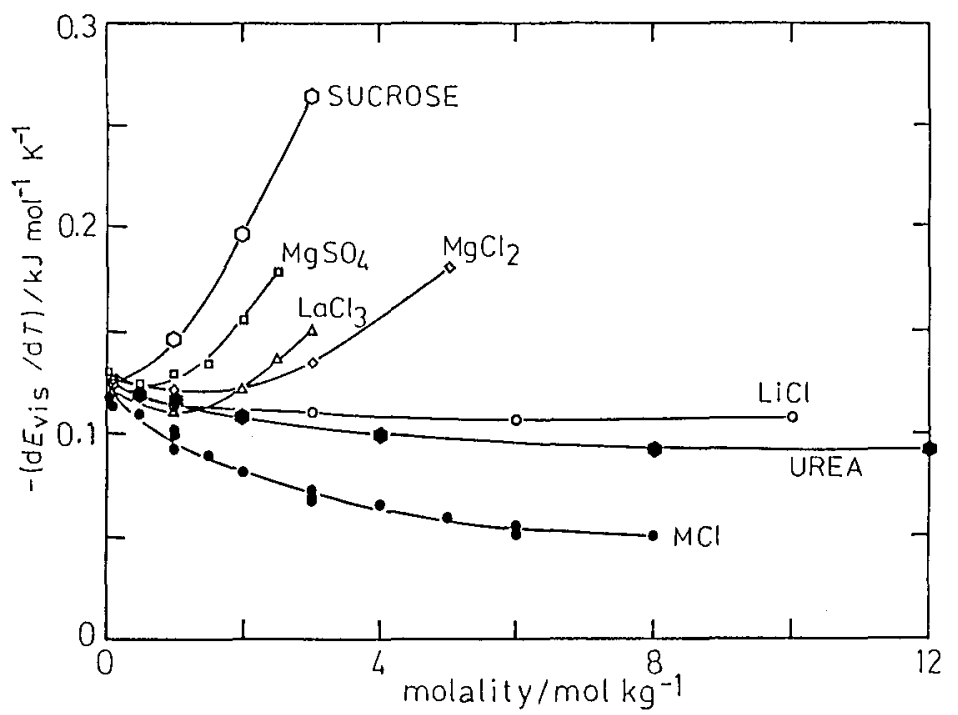

Fig. 2 Temperature derivatives of the activation energy for some aqueous solutions at $25^{\circ} \mathrm{C}$ as a function of molality of the solution: OLiCl, $\operatorname{MCl}\left(M=K, R b, C s\right.$ and $\left.\mathrm{NH}_{4}\right), \diamond \mathrm{MgCl}_{2}$, $\triangle \mathrm{LaCl}_{3}$, 口 $\mathrm{MgSO}_{4}, \bigcirc$ sucrose, urea

The present result gay be explained in terms of the Frank-Wen aspect of ionwater interaction 9 with the assumption that the temperature dependence of $\underline{E}_{v i s}$ reflects the structural change of water with temperature ${ }^{3}$.

In concentrated solutions of those solutes with larger magnitudes of (dEvis/dT), immobilized water molecules in the primary hydration shell will play an important role and structural break-down of the primary hydration

shell with increasing temperature will result in a large temperature dependence of the activation energy. In the ease of $\mathrm{KCl}, \mathrm{RbCl}, \mathrm{CsCl}$ and $\mathrm{NH}_{4} \mathrm{Cl}$, however, the contribution of the primary hydration shell to the structure of solution is considered to be less important in comparison with that of the secondary, structure-broken hydration shell; such an overall broken structure of the solution will give smaller temperature dependence of the activation energy.

\section{REFERENCES}

1) For example, E. C. Bingham, "Fluidity and Plasticity", McGraw-Hill, New York, Chap. III (1922); E. A. Moelwyn-Hughes, "Physical Chemistry", Pergamon, Oxford, pp.715-717 (1964).

2) R. C. Weast and M. J. Astle (ed.), "CRC Handbook of Chemistry and Physics", 59 th Ed., CRC Press, F-52 - F-57 (1978-1979).

3) P. Macedo and T. Litovitz, J. Chem. Phys., 42, 245 (1965).

4) M. L. Miller and M. Doran, J. Phys. Chem., 60, 186 (1956).

5) C. V. Suryanarayana and V. K. Venkatesan, Mh. Chem.,89, 824 (1958).

6) R. H. Stokes and R. Mills, "Viscosity of Electrolytes and Related Properties", Pergamon, Oxford, Chap. 7 (1965).

7) T. Satoh, J. Phys. Soc. Japan, 15, $1134(1960)$.

8) T. Isono, Rept. Inst. Phys. Chem. Res., 56, 103 (1980); J. Chen. Eng. Data, 29, 45 (1984); Rept. Inst. Phys. Chem. Res., 61, 53 (1985).

9) H. S. Frank and W.-Y. Wen, Dise. Faraday Soc., 24, 133 (1957). 